\title{
LAS POETAS TAMBIÉN VIAJAN AL PARNASO. TRADICIÓN LITERARIA Y DIFERENCIA DE GÉNERO EN LA POESÍA DIECIOCHESCA
}

\author{
Helena Establier Pérez \\ (Universidad de Alicante) \\ helena.establier@ua.es
}

\begin{abstract}
RESUMEN: La visita al Parnaso en clave femenina es un motivo que comparten en sus composiciones varias de las poetas españolas de las últimas décadas del XVIII y del período de entre siglos, como Clara Jara de Soto, Gertrudis de Hore y María Rosa de Gálvez. Este trabajo se centra en el estudio de este motivo de amplia tradición poética en varias composiciones de las tres autoras citadas donde adquiere matices novedosos, contribuyendo así a perfilar las vías por las que estas expresan en clave poética su conciencia de excepcionalidad y de marginalidad dentro del espacio literario de su tiempo.

PALABRAS ClAVE: Poetas, Parnaso, Género, Siglo XVIII, Escritoras.
\end{abstract}

\section{WOMEN POETS' JOURNEY TO PARNASSUS. LITERARY TRADITION AND GENDER DIFFERENCE IN EIGHTEENTH CENTURY SPANISH POETRY}

ABSTRACT: The return to classical literary subjects, such as the writer's journey to Mount Parnassus, is one of the strategies shared by three Spanish women poets in the last decades of the XVIIIth century and the beginning of the XIXth century: Clara Jara de Soto, Gertrudis de Hore and María Rosa de Gálvez. This paper focuses on the study of the theme mentioned above, the writer's journey to Parnassus, and its different presentations in the poems written by these three authors. The aim of our study is to show how these women poets express through their verses the awareness of their exceptionality and their marginality within the literary field at the turn of the century.

KEYWORDS: Women poets, Parnassus, Gender, XVIIIth century, Women writers.

La presencia femenina en la poesía española del período ilustrado fue palmariamente escasa, manifestándose de forma entrecortada y titubeante en el seno de un acalorado debate sobre la conveniencia y la validez de la escritura de las mujeres. Las pocas poetas que llegaron a publicar sus composiciones, bien en volumen, bien a través de la prensa, lo hicieron con plena conciencia de la trasgresión que suponía su intromisión en un ámbito cultural casi exclusivamente masculino, viéndose en la tesitura de implementar tácticas de adecuación a las prácticas líricas institucionalizadas, así como estrategias variadas de legitimación de su voluntad autorial. Entre estas últimas, la visita al Parnaso en clave femenina es un motivo que comparten en sus composiciones varias de las poetas de las últimas décadas del XVIII y del período de entre siglos, como Clara Jara de Soto, Gertrudis de Hore y María Rosa de Gálvez. A través del estudio de cinco poemas de estas tres autoras, publicados entre 1787 y 1804 , trataremos de mostrar a continuación cómo el tema clásico del viaje al Parnaso sirve a las escritoras dieciochescas para legitimarse como tales, pero también para expresar en clave poética una notoria conciencia de excepcionalidad y de marginalidad dentro del espacio literario de su tiempo. 


\section{DE VIAJES AL PARNASO Y DE POETAS DIECIOCHESCAS}

Tal como revelan los ilustrativos catálogos bibliográficos de Aguilar Piñal (1981, 1981-2002), la prensa española se convirtió a fines del siglo XVIII en el principal medio de difusión de la poesía de su tiempo. Las composiciones de este género, concebidas en su mayoría para satisfacer los gustos de los lectores de las secciones literarias de los diarios nacionales, tuvieron así una amplia recepción, que retroalimentaba la afición a escribir y leer versos como parte de los modos y de las modas socioculturales de las décadas finales de la centuria.

Esta furia versificatoria que inundó de forma muy especial las páginas de los periódicos españoles durante los veinte últimos años del setecientos, privilegiaba, más allá de la estricta elaboración poética, otras habilidades como la facilidad a la hora de hacer rimas, la improvisación, la cómoda adaptación sin mayor desarrollo a los metros y formas del país vecino o a esquemas considerados «modélicos», tales como las enseñanzas del Arte Poética de Díaz Rengifo (1592) u otros textos similares. Así las cosas, y pese a su aceptación popular —o quizá precisamente debido a esta-, dichas prácticas de urgencia poética consiguieron concitar las iras de algunos de los más relevantes teóricos del neoclasicismo español, como Leandro Fernández de Moratín, Juan Pablo Forner o Pedro Estala, quienes se afanaron por tratar de preservar las «divinas esencias» de la poesía nacional. Con este fin, los tres escritores, que compartían - junto a Juan Navarrete, León de Arroyal, Juan Antonio Melón y otros - una de las tertulias teórico-literarias más renombradas del XVIII, la organizada por el padre Estala (Arenas Cruz, 2003a: 37-40), fundaron en 1783 una imaginaria Academia Española, en cuyos estatutos afirmaban tajantemente «detestar la secta semigálica», admiradora y fiel seguidora de los usos literarios del país vecino, y se asignaban el estricto papel de «porteros del Parnaso». Asimismo, recogían como sus tareas fundamentales las de velar por «la poesía y la crítica castellanas, facultades ambas que andan descarriadas» — decían - , «y que por lo mismo necesitan acogida y abrigo para que no se pierdan», «defender a sangre y fuego el buen gusto castellano»y «obligarse a promover la afición a nuestros buenos escritores de los siglos XVI y XVII» (Cueto, 1869: CXLVI- CXLVII).

Enlazando con la misión de depuración literaria asumida por los miembros fundadores de esta Academia Española, en esos mismos años Estala, Moratín y Forner escribían sendas obras inspiradas en un mismo asunto, el viaje alegórico al Parnaso, y con idéntica finalidad: reflexionar sobre el estado de la literatura de su tiempo y satirizar a los pésimos poetas coetáneos.

Conviene recordar en este punto que el Parnaso, patria simbólica de los artistas, posiblemente haya sido - y con todas sus variantes - el lugar más citado en nuestra literatura clásica. ${ }^{1}$ Así nos lo explicaba Simón Díaz en su trabajo «El Monte Parnaso en cinco obras del Siglo de Oro» (1979), donde contaba por decenas de miles las referencias al sagrado monte helénico en las obras españolas de los siglos XVI y XVII, y citaba más de una docena - entre florilegios poéticos y piezas teatrales - que lo convertían en motivo fundamental y en parte de su título a lo largo de estas centurias. El

${ }^{1}$ El monte Helicón (consagrado a Apolo y a las musas,) o el monte Pindo, ambos cercanos al Parnaso, constituyen algunas de esas variantes. Entre los elementos del Parnaso más reconocidos literariamente hallamos la sagrada fuente Castalia, el río Céfiso, el oráculo de Delfos o el bosque de laureles, y entre sus ilustres moradores destacan las nueve musas, las ninfas y sobre todo Apolo, dios olímpico multifacético, patrón de la música y de la poesía, jefe supremo de las musas y director de su coro. 
estudio de Simón Díaz, pionero acercamiento crítico al tema del Parnaso en nuestra literatura clásica, se centraba en un grupo de obras, algunas de ellas bien conocidas -Viaje del Parnaso de Miguel de Cervantes (1614), Laurel de Apolo de Lope (1630), Coronas del Parnaso de Salas Barbadillo (1635), El Sacro Parnaso de Calderón (1659) - , coincidentes en su reelaboración del viaje de los poetas al sagrado monte y/o de las justas poéticas allí celebradas en presencia de Apolo.

Sin ánimo de profundizar en un asunto, el de las diferencias entre unas obras y otras, que no es objeto de este trabajo y que ya fue estudiado por Simón Díaz, resulta bastante evidente que todas ellas guardan algunos elementos en común: su carácter metaliterario - propician una reflexión sobre la literatura a partir de un enfrentamiento entre buenos y malos poetas $-^{2}$ y su vocación de contemplar la simbólica llegada al Parnaso como máxima aspiración compartida por integrantes y postulantes a la República de las Letras.

El viaje o visita al Parnaso se convierte así desde los Siglos de Oro en un referente del «clasicismo» poético, de forma que la insigne tríada de intelectuales ilustrados (Moratín, Forner y Estala) disponía ya en la década de 1780 de una tradición prestigiosa a la que acogerse en su voluntad de ensalzar la labor de los auténticos poetas - aquellos que seguían los modelos del verdadero clasicismo, la Antiguiedad clásica o el Renacimiento español, y que sabían combinar la técnica adquirida con el esforzado estudio, por un lado, y la fantasía ardiente, el buen ingenio, por otro-, frente a la de los «copleros» o «secta gálica» (afrancesada), es decir, los imitadores, improvisadores, poetas de circunstancias o «almas heladas», como los califica sin ápice de piedad el padre Estala. ${ }^{3}$

Con suma claridad lo expresaba Forner por vía de soneto:

¡Oh, cuánto fuera de la patria el gusto

Si una turba maldita de copleros

Tanta prosperidad no hubiera aguado! $!^{4}$

Pese al estímulo, las motivaciones y las fuentes comunes, las obras pergeñadas por cada uno de los tres eruditos a partir del motivo del viaje al Parnaso son claramente diferentes. La del crítico, helenista y traductor Pedro Estala - sin título, puesto que se halla intercalada en una miscelánea de textos producidos por la citada Academia Española entre 1783 y $1784-,{ }^{5}$ constituye un viaje burlesco al Parnaso, en prosa y verso, en el que un poeta acosado por una manada de «copleros» busca refugio en el

${ }^{2}$ El enfrentamiento alcanza diferentes grados en cada una de las obras. En el Viaje del Parnaso cervantino, por ejemplo, hallamos, más que un enfrentamiento verbal, una auténtica batalla campal en la que los malos poetas, que pretenden asaltar el Parnaso, lanzan libros y poemas a los buenos poetas y a Apolo, quienes a su vez defienden la exquisitez del sagrado lugar, quedando vencedores al final.

${ }^{3}$ En su versión del viaje al Parnaso, recogida por Arenas Cruz, satiriza precisamente Estala dos «sectas» de malos poetas: la de los seguidores del estilo gongorino, cuyas composiciones se hallan cuajadas de «conceptillos, equivoquillos, retruécanos y tiquismiquis», y la de los «gálicos», cuyo mérito consiste tan solo en «no faltarle ni sobrarle sílaba a ningún verso y en el rigor de los consonantes» (en Arenas, 2003b: 140).

${ }^{4}$ Son los últimos versos del soneto «Única infelicidad de España, en sus grandes felicidades» (en Cueto, 1871: 320).

${ }^{5}$ Entre los folios 161r y 171r del manuscrito (BNE ms. 3703) se encuentra este viaje burlesco al Parnaso, firmado por Damon, seudónimo del padre Estala. El texto lo reproduce Arenas Cruz (2003b: 136-147). Además, como apunta esta investigadora (133), el manuscrito comprende un prólogo que probablemente fuera redactado por Forner, varias composiciones del mismo autor firmadas como Amintas, una elegía de Mirtilo (Moratín), y una égloga de Batilo (Meléndez Valdés) y Arcadio (José Iglesias de la Casa). 
monte divino, es sabiamente aleccionado por Píndaro, finalmente perdonado por Apolo y enviado de nuevo a España para ahuyentar a los malos poetas.

Exequias de la lengua castellana, de Juan Pablo Forner, subtitulada «sátira menipea» y también comenzada entre 1783 y $1784,{ }^{6}$ es, sin embargo, una fantasía alegórica a modo de sueño fingido, en la estela de la República de las letras de Saavedra Fajardo, en prosa y con poesías intercaladas. En ella, Aminta (alter ego de Forner) y Arcadio (Iglesias de la Casa) son conducidos por Miguel de Cervantes hasta el Parnaso para acudir al funeral de la lengua castellana, pervertida y asesinada por una multitud de «escritorcillos». Finalmente, la lengua resulta no estar fenecida, sino solo agonizante, y todo lo experimentado por Aminta ha sido una suerte de «puesta en escena» con carácter preventivo urdida por Apolo para evitar la debacle del idioma castellano. Para despertar de su letargo a los ingenios nacionales, Apolo invita a Aminta a regresar a España y publicar su experiencia, instante en el que se produce el auténtico despertar del protagonista, que descubre haber estado soñando. Como señala el editor de las Exequias, José Jurado (2000: 1-li), a través del tono agridulce propio de la sátira menipea Forner «investiga las causas y orígenes de lo que él llama mal gusto en la literatura española», denunciando una y otra vez «el perjuicio que arrastra el afán de imitar lo francés, particularmente en la poesía; la profusión en el tiempo de copleros de ocasión, de escritorcillos corruptores de la lengua y de filósofos ganapanes».

La misma intención anima a Moratín a escribir La derrota de los pedantes. Sátira contra los vicios de la poesía española, que, aunque debió de concebirse al mismo tiempo que las dos anteriores, fue la única que se llegó a publicar en aquel entonces, concretamente en 1789, como folleto y sin el nombre del autor. En «Vida de don Leandro Fernández de Moratín», inserta en las Obras de D. Nicolás y D. Leandro Fernández Moratín, se explica así el origen de esta sátira:

Había en aquel tiempo la peste de malos poetas que en todas épocas; pero con la desgracia además de que eran aplaudidos por gran parte del pueblo, que ya admiraba sus rebozados e ininteligibles conceptos, ya se recreaba con sus frialdades e insulseces. Quiso Moratín distraer el mal humor consiguiente a su posición, ridiculizándolos según merecían, y en 1789 publicó su folleto titulado La derrota de los pedantes, en que algunos se vieron retratados, y no pudiendo perdonar al autor, en quien traslucían bajo el velo del anónimo la misma pesada mano que en su Lección Poética les había descargado sin piedad su primer azote (en Fernández de Moratín, 1857: XXVI).

En la obra de Moratín, única de las tres escrita íntegramente en prosa, un grupo de malos poetas, «docenas de pedantones, copleros ridículos» (1857: 561), intenta el asalto al Parnaso con gran estruendo, comandados por un autorzuelo que se enfrenta verbalmente a Apolo para exigirle su protección. Apolo, por supuesto, rechaza sus pretensiones, y la batalla, a la manera cervantina, está servida. Queda vencedor el bando del dios griego, integrado por los grandes literatos del Renacimiento, Mercurio y las musas, y finalmente, algunos de los malos copleros - los recuperables - son devueltos a casa, mientras que los considerados incurables quedan encerrados en jaulas.

Independientemente de sus diferencias, las tres obras responden a intereses comunes, provienen del mismo círculo, se componen en los mismos años y ofrecen, como no podía ser de otra manera, una visión absolutamente masculina del Parnaso, cuyas únicas moradoras son las musas y las ninfas al servicio de Apolo, y donde no se escuchan, por cierto, ni voces de autoridad femeninas ni las de posibles «copleras»

${ }^{6}$ François López (2001: 583-594) señala que la obra pasó por cuatro etapas de elaboración: 1783-1784, el bosquejo inicial; 1788, primera redacción; 1788-1793, segunda redacción con nuevos arreglos; 1795-1796, últimas modificaciones antes de que fuera entregada a Godoy. 
enjuiciadas. ${ }^{7}$ No tenía, desde luego, ninguno de los citados autores necesidad alguna de aludir a una modalidad, la poesía escrita por las mujeres, que tenía una presencia absolutamente anecdótica en tiempos ilustrados. Buen ejemplo de la escasa consideración otorgada a la lírica femenina en el XVIII lo ofrece uno de los compendios de mayor ascendiente entre los poetas neoclásicos nacionales: Parnaso Español. Colección de poesías escogidas de los más célebres poetas castellanos, de Juan José López de Sedano, publicado entre 1768 y 1778. Era este un macroproyecto erudito en nueve volúmenes, muy del gusto ilustrado, destinado a «servir de modelo para fixar el buen gusto de la Nación» en materia poética (López de Sedano, 1768: III-IV), para lo cual trataba de recoger las mejores muestras de nuestros poetas nacionales. Pese a su dilatada extensión, en sus nueve tomos y alrededor de 50.000 páginas, López de Sedano no incluye ni una sola composición con firma femenina.

Cierto es, en descargo de López de Sedano, que las contadas poetas dieciochescas, bien conscientes de la prudente distancia prescrita para las mujeres y la literatura por las convenciones de género vigentes, abordaban la creación lírica con escasa profesionalidad, por lo general como un divertimento ocasional del que derivaba una poesía efímera o de circunstancias, a veces manuscrita, ${ }^{8}$ otras publicada esporádicamente en forma de pliego ${ }^{9}$ o preferentemente en prensa ya hacia finales de la centuria. En ella precisamente aparecieron algunos poemas sueltos de autoras escasamente conocidas, como los de Clara Jara de Soto, Rosa Mazaorini y Magdalena Ricci en el Diario de Madrid, los de Isidra Rubio y María Martínez Abello en el Diario de Barcelona (Establier, 2015: 127-130), y otros de escritoras de más renombre como Gertrudis de Hore, algunas de cuyas rimas aparecen en el Correo de Madrid y en el Diario de Madrid.

Cierto es que entre estas autoras discretas también las hubo que dejaron un corpus lírico extenso y estimable, pero que por razones diversas, entre las que se cuenta seguramente el deseo de no transmitir una imagen pública de bachilleras, no llegó a ser editado o vio la luz póstumamente. ${ }^{10}$ Del mismo modo, ante el temor de la censura o del escarnio social, muy contadas fueron las poetas que asumieron públicamente su condición de sujetos autoriales, atreviéndose a desafiar las citadas convenciones de

\footnotetext{
${ }^{7}$ Solo un nombre de mujer se cuela en la obra de Moratín, y lo hace entre las obras del Barroco que lanza Mercurio a modo de proyectiles a los malos poetas durante la citada batalla: se encuentran allí las de la monja lisboeta sor Violante del Cielo, una de las escasísimas mujeres portuguesas — junto a Bernarda Ferreira de Lacerda, con su España Libertada (1673) - que logró publicar una obra propia en el Siglo de Oro. Quizá esta especial animosidad de don Leandro contra sor Violante tenga que ver precisamente con el atrevimiento de esta autora al apropiarse del monte sagrado en su obra Parnaso lusitano de divinos, e humanos versos (publicada póstumamente en 1733).

${ }^{8}$ Manuscritos quedaron, por ejemplo, los cuatro poemas que escribió Ignacia Sáenz de Tejada, conservados en la Biblioteca Nacional (MSS/12952/51).

9 En pliego publicaron sus respectivas poesías Isabel Catalina de Zavaleta (Afectuosas seguidillas a la feliz entrada de Su Majestad y altezas y enhorabuena a la reina madre nuestra señora, ¿1760?) y Josefa Céspedes (El parto de los montes. Bando que Apolo manda publicar contra los malos escritores, 1786).

${ }^{10}$ Buen ejemplo de ello es María Gertrudis de Hore, quien, además de las composiciones publicadas en prensa, escribió bastantes más, algunas destruidas por ella misma al profesar y otras recopiladas más tarde en forma manuscrita (en la Biblioteca Nacional se conserva un buen muestrario de poemas de «la hija del sol» en el Cancionero del siglo XVIII, MSS/3751, y en la Colección de poesías, MSS/4061). Otro ejemplo de modestia religiosa es sor Ana de San Jerónimo (Ana Verdugo de Castilla), cuyos poemas — Obras poéticas de la madre sor Ana de San Gerónimo - fueron publicados en 1773, a los dos años de su muerte. Por otro lado, las poesías de la canaria María Joaquina de Viera y Clavijo también se conservaron manuscritas en copias del siglo XIX (Biblioteca de El Museo Canario).
} 
género y a publicar sus versos en volumen para garantizar su conservación y posterior difusión, como hicieran, por ejemplo, María Rosa de Gálvez o Margarita Hickey. ${ }^{11}$

Sin duda, versos tan explícitos como las siguientes «Décimas a las damas del siglo ilustrado», donde la religiosa Nicolasa Helguero sanciona drásticamente la erudición femenina, ${ }^{12}$ contribuyen a explicar la prudencia de las mujeres a la hora de componer y — especialmente — de difundir públicamente sus rimas:

Las tropas de presumidas todo lo van destruyendo, y críticas van creyendo las tienen por entendidas. Juzgan estar instruidas con tal cual corta lección y que de la erudición gozan todos los primores. Tal disparate, señores, no le pensó Cicerón.

$[\ldots]$

Con las sierpes enroscadas, producción de las pelusas, se empeñan en ser medusas las señoras ilustradas. Con este hechizo adornadas, hacen piedras a las gentes, de las orejas pendientes están de varias cadenas, insensibles a las penas que dan estas delincuentes (Helguero, 1794: 238-240).

Ideas similares se vuelcan también en forma de reflexión o ensayo en la prensa de la época, como nos muestra, por ejemplo, este artículo anónimo del Diario de Barcelona en la misma década:

¿Qué es una mujer muy preciada de doctora (dice un filosófo) que va a establecer en su casa un tribunal de literatura, sino el azote de su marido, de sus hijos, de sus criados y de cuantos la tratan? [...] Semejante charlatanería es muy indigna de una matrona honesta: aun cuando tuviese verdadero mérito, su ridícula pretensión lo envilecería. La mayor dignidad de una mujer es ser ignorada del público; su gloria consiste en la estima de su marido; sus placeres deben ser la felicidad de su familia. ${ }^{13}$

${ }^{11}$ En 1789 aparece el primer y único volumen de Poesías varias, sagradas, morales y profanas o amorosas de Margarita Hickey. Sus poemas los edita y estudia Daniela Pierucci (2006). Traspasada la barrera del nuevo siglo, María Rosa de Gálvez publica sus Obras Poéticas (1804) en tres tomos, y además se hace visible como autora lírica en revistas literarias especializadas, tales como el Memorial Literario o Variedades de Ciencias, Literatura y Artes.

12 Pese a ello, la propia María Nicolasa Helguero y Alvarado publicaba en 1794 desde el convento de las Huelgas de Burgos una recopilación de versos titulada Poesías sagradas y profanas. Lo cierto es que, salvo unos pocos poemas al final del volumen destinados a prevenir a las mujeres contra los peligros del mundo, la mayoría de las composiciones incluidas en aquel son de inspiración mucho más divina que profana, lo cual justificaba la osadía autorial.

13 «Reflexión sobre la Literatura de las mujeres» se publicó en el Diario de Barcelona los días 4 y 6 de junio de 1799, en los números 155 y 157. 
Ante esta constante tensión, no resulta inhabitual entre las poetas dieciochescas, especialmente en aquellas que traspasan con su poesía el ámbito de lo privado, el tratar de compensar la osadía de su incursión en el terreno literario con estrategias diversas. Una de ellas es la de mostrar en sus composiciones un claro sesgo de género, feminizando conscientemente su poesía y buscando a través de los temas tratados o de su envoltorio formal la aquiescencia de los potenciales lectores y/o la empatía de las lectoras. Cultivan, así, la poesía religiosa, la de orientación didáctico-moral centrada en asuntos de interés para su propio sexo, la lírica amorosa desde la subjetividad femenina, etc., y muestran preferencias por una lírica «popular», compuesta a base de esquemas poéticos «modestos», acordes con la firma femenina que los acompaña. Es el caso, por ejemplo, de Margarita Hickey, que en varias de sus composiciones publicadas en volumen en 1789 asume la condición de sujeto amoroso femenino, pasivo y sufriente, que experimenta diferentes fases de la pasión y del desamor, o el de Gertrudis de Hore, diestra en las anacreónticas de estilo rococó repletas de idilios pastoriles (Morand, 2007).

En otras ocasiones, sin embargo, las tácticas de adaptación al medio empleadas por estas escritoras pasan por la voluntad de ajustarse a la ortodoxia lírica de su tiempo, de no discordar del canon establecido, recurriendo a las formas poéticas consagradas o demostrando su pericia compositiva en estrofas y subgéneros líricos de envergadura clásica, tal como demuestra María Rosa de Gálvez, quien de forma singular entre las autoras de su tiempo se esfuerza tanto en el cultivo de la poesía de circunstancias como en la de contenido áulico-patriótico.

Es ese mismo deseo de afianzar y justificar su propia labor el que impele a las poetas dieciochescas a buscar el respaldo de la autoridad o de la tradición literarias; y sin duda en este punto el viaje al Parnaso, asunto que disfrutaba de una larga y sustanciosa tradición en la historia de nuestra literatura y que había sido recientemente revitalizado por la publicación de los nueve volúmenes del Parnaso Español de López de Sedano (1768-1778), se les muestra como un motivo poético tan atractivo como susceptible de vehicular las inquietudes generadas por su doble y conflictiva condición de mujeres y poetas.

Así expresaba, por ejemplo, Rosa Mazaorini la ambición de gloria poética en un soneto publicado en el Diario de Madrid en 1796:

Sueña un calenturiento con la fuente, un viejo con un duelo en que ha vencido, sueña una niña amante en su querido, un celoso en traiciones del ausente.

Sueña una madre que los pasos siente del galán que otra vez fue sorprendido, un astrónomo sueña que ha medido la altura de los cielos eminente.

Sueña una hermosa que se ve adorada, un presidente, que aun los muertos cura, y un poeta novel ¿qué es lo que sueña?

Que ha subido del Pindo a la morada, sueña tal vez despierto; y su locura del oprobio al abismo le despeña. ${ }^{14}$

${ }^{14}$ Este «Soneto» sin título se publicó el 11 de septiembre de 1796 en el $n^{\circ} 255$ del Diario de Madrid, pp. 1041-1042. 
Así, y aunque los grandes ingenios del XVIII no se sintieran apelados por los versos femeninos, que no encontraron cabida en su particular concepción del Parnaso, veremos a continuación cómo, bien al contrario, algunas poetas se esforzaron por expresar sus aspiraciones legítimas a brillar en el monte de Apolo o, cuando menos, a asomarse a él.

tres poetas ilustradas en el Parnaso: Gertrudis de Hore, Clara Jara De Soto Y MARÍA ROSA DE GÁLVEZ

La conciencia de las dificultades inherentes al camino hacia la República de las Letras no fue óbice para que en el período de entresiglos, y coincidiendo con los debates en la prensa sobre las aptitudes femeninas para el cultivo del intelecto, varias poetas actualizaran en sus composiciones el tema del Parnaso con intención reivindicativa o, cuando menos, constatativa de sus aspiraciones a los divinos laureles.

La primera de ellas en términos cronológicos fue la monja gaditana Gertrudis de Hore, en un «Soneto» («Estaba Apolo en el Parnaso un día...») que publicó en el Diario de Madrid en 1787, nueve años después de tomar los hábitos, ${ }^{15}$ pero que probablemente fuera escrito con anterioridad. ${ }^{16}$ En él hallamos la primera muestra dieciochesca de feminización del viaje al Parnaso, protagonizado en el soneto por una poeta de procedencia bética y seudónimo pastoril - Fenisa-, el mismo que Gertrudis de Hore adoptaba en otras de sus composiciones:

Estaba Apolo en el Parnaso un día, repartiendo guirnaldas diferentes, y de Helicona al son de las corrientes Terpsícore festiva danzas guía:

Fenisa, que del Betis ascendía, osada llega entre otras concurrentes, y al ver de todas coronar las frentes «¿dónde está», dice, «la corona mía?»

Febo, al verla de galas adornada, «Aparta», le responde, «la riqueza con mi numen feliz no tiene entrada», a que ella le replica con presteza:

«Si esto no más en mí te desagrada, coróname, que admito la pobreza».

Además de la novedosa presencia de una concurrente en el reparto de laureles realizado por Apolo, el soneto de Hore ofrece algunas otras claves interesantes para desgranar las particularidades que alcanza en las poetas dieciochescas el cultivo de este motivo de sólida tradición clásica. En este sentido, el segundo cuarteto deja claro que la osadía de Fenisa al ascender al Parnaso, lejos de ser una excepción en un mundo poético totalmente masculino, es compartida por una cohorte de escritoras que son merecedoras de la guirnalda divina: «osada llega entre otras concurrentes, / y al ver de todas coronar

\footnotetext{
${ }^{15}$ Morand (2003: 145) indica que la entrada de Gertrudis de Hore en el convento de Santa María de Cádiz se produjo el 14 de febrero de 1780.

${ }^{16}$ El soneto en cuestión se había publicado en el Semanario de Cartagena el 30 de noviembre de 1787 (número XLVIII) y lo recoge de nuevo el Correo de Madrid un mes más tarde (19 de diciembre). Eustaquio F. de Navarrete, en el manuscrito de poemas de la autora conservado en la Biblioteca Menéndez y Pelayo de Santander entre los papeles de Valmar y que le sirvió a Cueto para la publicación de sus composiciones en la BAE, apunta que fue «escrito poco antes de renunciar al mundo» (en Morand, 2003: 240). Por la temática y el tono, bien pudiera ser así.
} 
las frentes». ${ }^{17}$ Evidentemente, aunque este universo femenino sea motivo habitual en la obra de Hore, resulta absolutamente novedoso en la formulación de la visita al Parnaso, tal y como la hallamos en la tradición anterior a la escritora gaditana, donde, como ya hemos señalado, solo se contempla la escritura de las mujeres de forma excepcional y con afán reprobatorio, como en el citado caso del Parnaso Español de López de Sedano con la portuguesa Violante del Cielo. Lo inaudito de la pretensión de Hore al adornar el Parnaso con abundantes laureles femeninos lo certifica la versión del mismo poema publicada años después por Leopoldo Augusto de Cueto en su antología de Poetas Líricos del Siglo XVIII (1871). Este soneto de Gertrudis de Hore es, de hecho, la única composición escrita por una mujer entre los más de tres millares de poemas que recoge el marqués de Valmar, quien introduce una curiosa variación en los dos versos citados más arriba: «osada llega entre otros concurrentes, / y al ver de todos coronar las frentes». ${ }^{18}$ No deja de ser interesante que Cueto, al recoger una única composición de factura femenina y anular cualquier sugerencia - dentro y fuera del poema de Hore - acerca de la posibilidad de un Parnaso en femenino, le devuelva al sagrado monte su condición de olimpo poético masculino en el que la monja gaditana no representa sino una anomalía, una excentricidad que no puede llegar a constituir la norma.

En ambas versiones, al reclamarle Fenisa al dios Apolo su guirnalda de laurel — ¿¿dónde está, dice, la corona mía?»-, Hore revela que la poeta se siente merecedora de ese galardón sagrado en idéntica medida en que así lo estimaban el coplero de La derrota de los pedantes o los escritorzuelos de las Exequias fornerianas. La tajante réplica de Apolo — «Aparta [...] la riqueza con mi numen feliz no tiene entrada» - indica que, si bien a Fenisa se le niega la corona divina, la razón no estriba, como en el caso de Moratín o de Forner, en la falta de maestría lírica de la aspirante, sino en la voluntad de Hore de ofrecer una lección de humildad y de militancia poética femenina; así, la perentoria respuesta de Fenisa — «coróname, que admito la pobreza»— implica un auténtico compromiso vital de la poeta con su arte: la austeridad personal y poética a cambio de la corona apolínea, la renuncia a las galas mundanas para disfrutar plenamente de las del intelecto.

Interesante resulta el contraste entre este soneto temprano y alguno de los poemas que Hore escribe años después desde el claustro, en los que condena la ansiedad de gloria poética y apuesta, con mayor o menor sinceridad, por una lírica religiosa, sin otra ambición que la de servir a Dios y perfeccionar el alma. ${ }^{19}$ Así lo observamos, por ejemplo, en los siguientes fragmentos de la anacreóntica «¿Hasta cuándo, Gerarda?» (Diario de Madrid, 9 de agosto de 1795), en la que Hore vuelve sobre el motivo del Parnaso para prevenir a otras posibles cantoras, como su amiga Gerarda, de la superfluidad de la ambición poética e invitarlas a buscar en la religión el motivo de inspiración de sus versos:

Yo también invocaba

al que llaman Dios ciego,

e hice (;rara locura!)

me prohijara Febo.

${ }^{17}$ El resaltado es mío.

${ }^{18}$ El resaltado es mío.

19 Señala Palacios Fernández (2002: 144) que los versos posteriores a su ingreso en religión cambian de signo, que «el amor se convierte en desengaño y su sentir poético se llena de notas de reflexión, soledad y amor a Dios». No coincide Morand (2003: 90-91), sin embargo, en esta dicotomía propuesta por Palacios para la obra poética de la autora a partir de su entrada en el claustro; ella, por el contrario, observa continuidad vital y poética entre ambas épocas. 
Yo lloré ingratitudes, yo celebraba afectos, empleando en delirios la dulzura del metro. Pero ya arrepentida de tan frívolo empleo solo a dignos asuntos dedicarle pretendo [...] Tú, amada compañera, sigue también mi ejemplo, no aguardes que algún día lo exija el escarmiento [...] Nuestra común amiga sea tu nuevo Febo, ella te preste especies a tus primeros versos. [...] Del más sacro Parnaso subirás a lo excelso, y al monte de Helicona mirarás con desprecio.

En definitiva, si en el soneto anterior las aspiraciones intelectuales anulaban los bienes mundanos y se erigían en prioritario anhelo vital, en la anacreóntica de 1795 el Parnaso de Hore se ha sacralizado, y en consecuencia la gloria del alma femenina ya no puede enraizarse en la literatura, sino que ha de derivar de la renuncia expresa a las satisfacciones del ego, como son las propias ambiciones poéticas.

Otra de las poetas dieciochescas que emprende viaje poético al Parnaso, aunque con intenciones bien diferentes, es Clara Jara de Soto, en una desconocida letrilla publicada por la autora en el Diario de Madrid el 4 de octubre de 1790: ${ }^{20}$ «Letrilla que compuso doña Clara Jara de Soto, fingiendo haberse hallado en sueño en el Tribunal de Apolo». Conviene recordar en este punto que en abril del mismo año la autora había solicitado permiso para imprimir Tertulias murcianas y segunda parte del instruido en la corte y aventuras del extremeño, manuscrito que, según apunta el expediente de censura, contenía una comedia y varias novelas. ${ }^{21}$ La censura, que se encargó a la Real Academia de la Historia y que fue realizada por José de Vargas Ponce, ${ }^{22}$ resultó demoledora, y aunque el poeta y erudito gaditano no proscribía explícitamente la

${ }^{20}$ Poco antes, el 13 de agosto de 1790 (número 225), había publicado la autora en el mismo Diario otra letrilla firmada con sus iniciales («Nuestro Dios piadoso...») acerca de la ingratitud humana. Dicha letrilla iba seguida de un soneto anónimo en el que se identificaba a la autora («Clara luz que el Jaral del Soto anima...») y se ensalzaba su quehacer poético: «Y el Parnaso vencido a tus pies gima». No parece, desde luego, que este fuera el caso para Jara de Soto.

${ }^{21} \mathrm{El}$ año anterior, en 1789, la autora había publicado ya una novela original, El instruido en la corte y aventuras del extremeño (Madrid, Imprenta de Joseph Doblado), evento absolutamente extraordinario entre las escritoras de su tiempo. A la luz de las letrillas aparecidas en el Diario de Madrid y de esta novela, parece evidente que a la autora le gustaba el cultivo del género satírico, en prosa y en verso; la novela, en la línea del costumbrismo crítico-moral, se encuentra salpicada de algunos poemas (décimas y seguidillas) de corte popular y sumamente ingeniosos. Su segunda obra, Tertulias murcianas y segunda parte del instruido en la corte, no se conserva.

${ }^{22}$ El citado informe de censura, con fecha de 29 de abril de 1790, y el certificado de Antonio de Capmany sobre dicho informe (de 4 de mayo de 1790) se encuentran en la Real Academia de la Historia (M-RAH 11/8013-8028). 
publicación de la obra, la Academia decidió que el manuscrito de Jara de Soto no mudara de estado. ${ }^{23}$

A la luz de esta estricta censura y de la consiguiente recomendación de la RAH, que debieron de incomodar en grado sumo a la autora, conviene entender el contenido de la letrilla que publica apenas cuatro meses después en el Diario de Madrid (del 4 de octubre de 1790), arremetiendo con ironía contra las instituciones literarias. En dicho poema, siguiendo el modelo de la República de las Letras de Saavedra Fajardo o de las citadas Exequias de Forner, la autora (1790: 1111-1112) en su sueño es reclamada por Apolo y sus nueve musas:
Acosteme anoche
triste, y pensativa,
y entre confusiones
me quedé dormida;
pero a poco rato
cierta hermosa ninfa
hacia mí se viene,
y con melodía
me intima un decreto,
el que así decía:
El señor Apolo,
con sus nueve hijas,
me manda decirte
que a su juicio asistas:
quedeme confusa
al oír tal noticia,
$\mathrm{y}$ me fue preciso
su orden cumplirla.

Llegada al Parnaso, y en lugar del divino laurel, encuentra a una encolerizada Talía, solicitándole al dios griego la reprobación de la autora por sus defectuosos versos y su necio afán de emular a las maestras de la Antigüedad:
Esta que aquí viene muy desvanecida, castigarse debe porque necia aspira a que el vulgo piense, viendo sus coplillas, que yo la he inspirado ser Safo o Corina, cuando tantas faltas en ella se miran.

${ }^{23}$ Tal como señala Capmany en el citado certificado, el censor, comparando las novelas de Jara de Soto con las de su más renombrado precedente en narrativa femenina, María de Zayas, encontraba que «con menos corrección en el estilo ni felicidad en la invención, tienen todos los defectos de aquellas, sin un fin moral conocido, sin episodios que instruyan o interesen, sin variedad que divierta». Por su parte, la comedia, «sin observar una tan sola de las reglas teatrales, tiene todos los defectos de falta de verosimilitud, de frialdad en el diálogo; que los caracteres, ni son verdaderos, ni están sostenidos; que la trama, ni está bien seguida, ni su desenlace es natural». Aun así, Vargas Ponce indicaba en su informe que no veía razón que impidiera su publicación. La Academia, sin embargo, decidió en otro sentido. 
La respuesta del dios olímpico a Talía, en el tono mordaz y juguetón de las letrillas populares, nos ofrece el primer reproche de Jara de Soto a la inteligencia nacional por la escasa consideración en que esta tiene a la literatura femenina: según sentencia Apolo, ni procede que Talía, advenediza en el círculo de los «Poetas»—resáltese la mayúscula—, se ejercite en hacer versos, ni puede pretender que, siendo mujer y «lega», su obra sea estimada por los altos ingenios y censores:

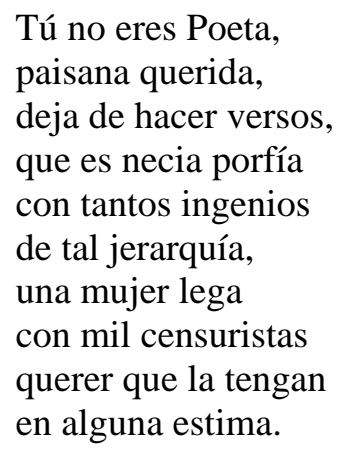

Llegada la ocasión de valorar las obras de la ingenua aspirante a los laureles del Parnaso, Jara de Soto vuelve a servirse del tono burlesco para denunciar la intransigencia de los «poderes» literarios. Así, Apolo ordena que la poeta sea aislada en su desvarío literario por todos aquellos que deseen ingresar en su divino gremio («Dejadla por loca, / que en eso los días / pasa sin perjuicio, y está divertida: / solo mando a todos / los que a ser aspiran / de mi gremio, nunca / compren sus poesías»), acomodando su sentencia a la conclusión de la citada censura de Vargas Ponce sobre las Tertulias murcianas, donde, tras vapulear a conciencia la obra de Jara de Soto, concluía no tener objeción alguna para su publicación: «y que su instruido / segundo se imprima, / y se desengañe / que nadie le estima».

Los últimos versos de la letrilla, siguiendo la tradición del modelo al que se acoge, incluyen el despertar del sueño, seguido de la aplicación de la fantasía onírica a las vicisitudes editoriales sufridas por la autora:

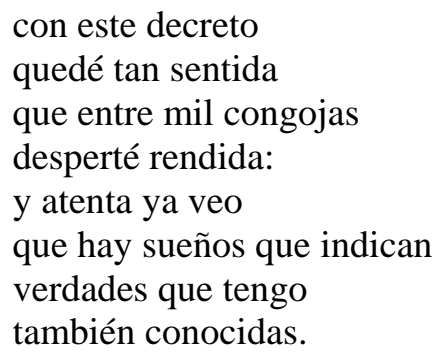

Es evidente la intertextualidad de esta composición con la censura de las Tertulias murcianas, así como la voluntad de la autora de servirse del molde satírico de la letrilla para expresar líricamente tanto la contrariedad que le produce la reprobación de su obra como su mordaz opinión sobre la posición periférica y subalterna de las mujeres en la literatura de su tiempo: el Parnaso se revela en su poema como un imposible para las escritoras; Apolo - dios, y como tal, hombre- da voz en él a esos implacables censores de la Real Academia de la Historia que arremetieron contra su obra; y la protagonista, proyección de sí misma, es esa escritora «lega» que, como Talía (siempre mujer antes que musa), no debe hacer versos por sus evidentes limitaciones en instrucción y en técnica poética, lo cual le cierra las puertas del Parnaso, de la Academia y, según el protocolo editorial de su tiempo, también de la imprenta. 
No fue tal, sin embargo, la suerte de las obras de la última autora a la que nos referiremos, María Rosa de Gálvez, quien, como bien estudia García Garrosa, probablemente sea la escritora con más conciencia literaria de su tiempo (2017: 429) y con mayor afán de alcanzar los divinos laureles de Apolo. De hecho, tal como indicábamos al comienzo de este trabajo, Gálvez es una de las escasísimas autoras dieciochescas que emprende el tortuoso camino de conducir sus obras a la imprenta, consiguiendo con no pocas dificultades publicar nada menos que tres volúmenes de Obras poéticas en 1804. Precisamente en una de las composiciones incluidas en el tomo I - que aglutina el grueso de su producción lírica-, ${ }^{24}$ y dedicada «A la Poesía», confesaba la autora (1804, I: 25-26) lo siguiente:

Así mis versos por tu sabio amparo

la envidia vencen y el temor desprecian.

Mi genio aspira a verse colocado

en el glorioso templo de la fama.

El acceso al templo de la fama fue una de las mayores inquietudes de Gálvez, aunque lo cierto es que, tras una carrera literaria tan breve como intensa, la poeta y dramaturga malagueña acabó siendo considerada un referente inexcusable del «Parnaso femenino» de su tiempo, como bien muestran las valoraciones contemporáneas de sus poemas (Bordiga Grinstein, 2003: 57-59; García Garrosa, 2017: 448-452). Así lo reconocía, por ejemplo, Manuel José Quintana en su crítica a las Obras poéticas de la escritora, publicada en Variedades de ciencias, literatura y artes:

nuestra literatura, que entre las mujeres que se habían dedicado a componer versos, no contaba sino escritoras de coplas, puede desde ahora darse el parabién de tener un talento que al interés que llama hacia sí su sexo, reúne el mérito de haber producido un buen número de rasgos verdaderamente poéticos, que no solo le harán respetable mientras viva, sino que pasarán su nombre a la posteridad (Quintana, 1805: 164).

En dos composiciones recogidas en ese mismo primer volumen de sus Obras poéticas, María Rosa de Gálvez expresaba poéticamente su inquietud por llegar a alcanzar el templo de la fama: la oda «En los días de un amigo de la autora» y unos versos sáficos dedicados, precisamente, al poeta Quintana ( «A don Manuel Quintana en elogio a su oda al océano»).

En ambos casos, la referencia al Parnaso se vehicula a través de la poesía de circunstancias, celebrativa, especialmente grata a los autores ilustrados pero de escasa aceptación entre las escritoras, a excepción de la propia Gálvez, quien, en su afán de medirse con los grandes ingenios de su tiempo, la practica en no pocas ocasiones. ${ }^{25}$ En este sentido, tanto por el molde elegido, propio de la vertiente más solemne de la poesía ilustrada, como por el contenido, estos dos poemas son especialmente reveladores de su deseo de alcanzar la maestría poética, de emular a esos ilustres vates tocados por la gracia de Apolo, mientras que, al hilo, traducen al verso la ansiedad autorial de Gálvez,

\footnotetext{
${ }^{24}$ Para una valoración conjunta de su producción poética, ver las páginas que le dedican Bordiga, 2003: 35-59; Palacios Fernández, 2002: 160-170 y Luque, 2007.

${ }^{25}$ Véanse, por ejemplo, su Oda en elogio de la marina española (Madrid, Repullés, 1806) y los siguientes poemas recogidos en sus Obras poéticas de 1804: «La beneficencia: oda a la Excma. Sra. condesa de Castroterreño, con motivo del discurso que pronunció en la Real Junta de Damas en elogio de la reina nuestra señora», «La campaña de Portugal: oda al Excmo. señor Príncipe de la Paz», «Las campañas de Buonaparte en Italia: oda», «En elogio de la representación de la opereta intitulada "El delirio", ejecutada en el Coliseo del Príncipe: oda», «La noche: canto en verso suelto a la memoria de la señora condesa del Carpio», etc.
} 
quien vuelca en ellos sus inseguridades poéticas, la conciencia de sus propias limitaciones «femeninas»-falta de erudición y de técnica-, tal como reconoce también en algunos de los prólogos en prosa a sus obras. ${ }^{26}$

En la primera de las dos composiciones, «En los días de un amigo de la autora», el viaje al Parnaso tiene como motivo el aniversario de un poeta afín a la escritora, al que Gálvez cita como «Sabino». La autora (1804, I: 35), bajo el anagrama de «Amira» (María), abandona entonces su apacible estado para aproximarse al templo de las musas, donde los dioses congregados y comandados por Apolo celebran el aniversario del amigo Sabino:

\author{
Por llegar a la cumbre \\ del Parnaso eminente, \\ dejaba alegre mi apacible choza, \\ antes que por las puertas del oriente \\ la brillante carroza \\ de la rosada aurora \\ fuese de la de Febo precursora. \\ A celebrar los días \\ felices de Sabino \\ al templo de las musas me acercaba, \\ cuando escuché sonar eco divino \\ que el Pindo alborozaba \\ y en confusa armonía \\ el nombre de Sabino repetía.
}

Sabino ya ha encontrado su lugar en el divino monte ( $«$ Sabino conducido / por la fama y la gloria / sin orgullo sentose») y Amira, estimulada por el reconocimiento obtenido por su amigo, le solicita que la inspire con sus versos:
Arrebatada
yo entonces de su dicha, hice memoria
de mi lira olvidada,
y esperé que algún día
su silla se igualase con la mía.
«Anima, caro amigo,
(le dije) con tu ejemplo,
los versos de mi numen atrevido;
porque la fama en su glorioso templo
librarlos pueda del oscuro olvido» (36-37).

Ante sus requerimientos, Sabino la tienta, la induce a beber de la fuente Castalia para conseguir la fama inmortal con su poesía; no en vano, recuerda Sabino, el agua sagrada del Parnaso inspira «el amor celestial de las virtudes», las cuales, al inflamar el corazón con su fuego, llevan el canto del poeta a la «inmortal fama» (37). Sin embargo, en esta recreación a la inversa del conocido motivo de la tentación bíblica, la visita al

${ }^{26}$ Así lo confesaba, sin ir más lejos, en la «Advertencia» que antecede al primer volumen de sus Obras poéticas (1804, I: s.p.): «Las poesías líricas impresas en este tomo son por la mayor parte hijas de las circunstancias; y solo las presento como una prueba de lo que he podido adelantar en este género. Tales cuales sean unas y otras, confieso ingenuamente que no es mi ánimo entrar en competencias literarias con los que corren por poetas entre nosotros. Conozco la diferencia que hay entre unos talentos mejorados por el estudio, y una imaginación guiada solo por la naturaleza». 
monte Parnaso y las aguas de su fuente causan en Amira un efecto distinto al pretendido:

\author{
Yo bebí, y en mi seno \\ sentí que, poseído \\ mi dócil corazón de ardores puros, \\ los afanes de amor daba al olvido; \\ $\mathrm{y}$ en los tiempos futuros, \\ de la sabia natura \\ señalará este día la ventura (37).
}

La aspiración a la gloria literaria queda así postergada ante una suerte de catarsis personal de Amira, una transformación de su experiencia vital que la conduce a olvidar las cuitas amorosas y a avistar esperanzada el comienzo de un nuevo tiempo, de felicidad, de amor celestial y «ardores puros».

Frente a esta placentera experiencia de celebración poética de la amistad, concluida felizmente en la postergación de las ambiciones literarias y en la recuperación del equilibrio emocional de la autora, en el segundo de los poemas citados de Gálvez, «A don Manuel Quintana en elogio a su oda al océano», Amira tiene el atrevimiento de querer ascender al Parnaso impulsada por sus pretensiones literarias y por su vanidad:

Quise, atrevida, del sonoro Pindo

hollar la falda, y el orgullo necio

hasta la cumbre del celeste monte

con vano aplauso mi ambición conduce (Gálvez, 1804, I: 46).

Cuando la orgullosa poeta llega al sagrado monte, es rápidamente desengañada en su ambición por Apolo, quien le explica que la suya es una aspiración vana, le recomienda que se aplique en el estudio y que se fije en modelos de excelencia, como la «Oda al océano» de Manuel José Quintana:

En vano, Amira, con tu lira quieres

en el Parnaso colocar tu nombre;

busca modelo que tu genio guíe;

oye a Quintana, que en su canto pinta

del ancho Ponto las bullentes ondas.

$[\ldots]$

Amira, deja tu orgulloso intento:

con nuevo estudio mejorar procura

el canto antiguo de tu humilde lira;

y elogia entonces de Quintana el numen,

honor y gloria de la musa hispana (47-48).

El discurso de Apolo a Amira es un canto a las excelencias de la oda del escritor madrileño, quien, como hemos señalado antes, correspondió unos meses más tarde a las encendidas alabanzas de Gálvez con una crítica bastante complaciente de sus Obras poéticas en Variedades de ciencias, literatura y artes. En la última estrofa del poema de la autora malagueña, Amira reconoce su impericia y, como parte de ese juego constante entre modestia femenina y vanidad literaria en el que Gálvez es especialmente diestra, aquella le solicita con humildad a Apolo que la inspire para su composición en honor a Quintana, versos que obviamente a estas alturas ya han quedado escritos. 
En definitiva, los poemas analizados de Jara de Soto, Hore y Gálvez ofrecen una variante novedosa en la literatura femenina del siglo XVIII: la reelaboración del tópico del viaje al Parnaso desde su experiencia singular de mujeres que componen versos, de sujetos autoriales sexuados, sometidos a una estricta división de roles que desautorizaba expresamente la actividad intelectual femenina, y necesitados por tanto de constante legitimación. En el caso de estas escritoras, su interés por cultivar el tema no estriba en la idoneidad y oportunidad de este para impartir lecciones poéticas de preceptiva y buen hacer literario o para institucionalizar el canon, como ocurría en los citados precedentes del propio siglo; de hecho, el nuevo sujeto lírico femenino en el tránsito entre dos centurias no visita el Parnaso como pretexto para elaborar una poética, ni tampoco para hacer un ejercicio de autoridad literaria, como marcaba la tradición, sino como testimonio de su yo de mujer, como estrategia de refrendo, como recurso para dar cuenta de una aspiración propia - la de hacer versos de forma pública - que se hallaba aún excluida del canon femenino vigente.

Es evidente que entre ellas hay diferencias de tono, forma e intención. Gertrudis de Hore se sirve de este motivo doblemente y en sentidos aparentemente opuestos: primero para ratificar su absoluto compromiso con la poesía, y años más tarde, tras su ingreso en religión, para garantizar que sus inquietudes espirituales han desterrado a las literarias y prescribir un modelo de aspiraciones femeninas alejado de la vanidad poética. Clara Jara de Soto, por su parte, lo reformula en tono satírico-burlesco para cuestionar las razones de su exclusión, en tanto que mujer y escritora, de las altas esferas literarias, así como para visibilizar los velados y arbitrarios escollos a los que había de enfrentarse a finales del siglo XVIII la escritura femenina. Años después, ya traspasada la barrera del cambio de siglo, Gálvez vuelve sobre el asunto en clave poética y con afectada humildad para confesar y justificar unas aspiraciones de gloria que venía demostrando con creces en su trayectoria dramática.

Más allá de estas diferencias superficiales, las tres coinciden en el fondo del asunto: la presencia femenina en la república literaria es una novedad, pero también es una aspiración legítima, hasta tal punto que les permite apropiarse de un motivo clásico como el viaje al Parnaso y revisitarlo desde su diferencia de género, en virtud de unos intereses y de una finalidad diferentes.

Decía irónicamente Fernández de Moratín en La derrota de los pedantes que para hacer versos bastaban tres cosas: comprar un Rengifo por tres pesetas, un poco de práctica y otro poco de vergüenza. Parece lícito preguntarse cuál hubiera sido el juicio literario de la Academia Española de Forner, Moratín y Estala acerca de estas «copleras», como Jara de Soto, Hore y Gálvez, que pretendían ser poetas con estudios limitados, escaso soporte socioliterario y mucho arrojo. No llegaremos a saberlo a ciencia cierta, pues tal y como hemos señalado, en ninguno de sus viajes al Parnaso se hacen eco de la poesía femenina. Desde la óptica ilustrada, el sagrado monte de Apolo no era un lugar para las mujeres, aunque las poetas, ya lo hemos comprobado, discrepasen en verso sobre este punto.

\section{OBRAS CITADAS}

Aguilar Piñal, Francisco (1981), Índice de las poesías publicadas en los periódicos españoles del siglo XVIII, Madrid, CSIC.

Aguilar Piñal, Francisco (1981-2002), Bibliografía de autores españoles del siglo XVIII, 10 vols., Madrid, CSIC.

Arenas Cruz, María Elena (2003a), Pedro Estala, vida y obra. Una aportación a la teoría literaria del siglo XVIII español, Madrid, CSIC, Instituto de la Lengua Española. 
Arenas Cruz, María Elena (2003b), «Un viaje al Parnaso de Pedro Estala», Dieciocho, XXVI, 1, pp. 131-161.

Bordiga Grinstein, Julia (2003), La Rosa trágica de Málaga: vida y obra de María Rosa de Gálvez, Dieciocho, anejo 3.

Cueto, Leopoldo Augusto de (1869), «Bosquejo histórico-crítico de la poesía castellana en el siglo XVIII», en Poetas líricos del siglo XVIII, tomo I, Madrid, Rivadeneyra, pp. VCCXXXVII.

Cueto, Leopoldo Augusto de (1871), Poetas líricos del siglo XVIII, tomo II, Madrid, Rivadeneyra.

Establier Pérez, Helena (2015), «María Martínez Abello y la comedia nueva de entresiglos en clave femenina: Entre los riesgos de amor, sostenerse con honor. La Laureta (1800)», Dieciocho. Hispanic Enlightenment, 38, pp. 125 - 152.

Fernández de Moratín, Nicolás y Leandro (1857), Obras de D. Nicolás y D. Leandro Fernández de Moratín, Biblioteca de Autores Españoles, Madrid, Rivadeneyra.

Gálvez, María Rosa de (1804), Obras Poéticas, 3 vols., Madrid, Imprenta Real.

García Garrosa, María Jesús (2017), «María Rosa de Gálvez: la ambición del Parnaso», en Elena de Lorenzo Álvarez (coord.), Ser autor en la España del siglo XVIII, Gijón, Trea, pp. 429-454.

Helguero y Alvarado, María Nicolasa (1794), Poesías sagradas y profanas, Burgos, José de Navas.

Hickey, Margarita (2006), Poesías, ed. Daniela Pierucci, Pisa, Edizioni ETS.

Jara de Soto, Clara (1790, 4 de octubre), «Letrilla que compuso doña Clara Jara de Soto, fingiendo haberse hallado en sueño en el Tribunal de Apolo», Diario de Madrid, 277, pp. 1111-1112.

Jurado, José (ed.) (2000), Exequias de la lengua castellana, sátira menipea, Madrid, CSIC.

Lopez, François (2001), Juan Pablo Forner (1756-1797) y la crisis de la conciencia española, Valladolid, Consejería de Educación y Cultura.

López de Sedano, Juan José (1768), Parnaso Español. Colección de poesías escogidas de los más célebres poetas castellanos, I, Madrid, Joaquín Ibarra.

Morand, Frédérique (2003), Doña María Gertrudis de Hore, 1742-1801. Vivencia de una poetisa gaditana entre el siglo y la clausura, Alcalá de Henares, Ayuntamiento.

Morand, Frédérique (2007), Una poetisa en busca de libertad: María Gertrudis de Hore y Ley (1742-1801): miscelánea y taraceas de versos, prosas y traducciones, Cádiz, Diputación.

Palacios Fernandez, Emilio (2002), La mujer y las letras en el siglo XVIII, Madrid, Ediciones del Laberinto.

Quintana, Manuel José (1805), «LITERATURA: Obras Poéticas de Doña María Rosa Gálvez de Cabrera. Tres tomos en octavo. Madrid, en la Imprenta Real, año de 1804», Variedades de Ciencias, Literatura y Artes, 3, año II, tomo I, Madrid, Oficina de Benito García y Compañía, pp. 159-164.

Simón Díaz, José (1979), «El Monte Parnaso en cinco obras del siglo de Oro», Anales de literatura hispanoamericana, 8, pp. 273-288.

Zorrozua, Pilar (1999), Escritoras de la Ilustración española, Tesis Doctoral, Bilbao, Dpto. de Publicaciones de la Universidad de Deusto. 